\title{
A Comparative Study of Gamified and Conventional Online Quizzes
}

\author{
https://doi.org/10.3991/ijet.v17i03.26349 \\ Kyung-Mi O \\ Dongduk Women's University, Seoul, Korea \\ kmo@dongduk.ac.kr
}

\begin{abstract}
This study explored students' perceptions about using gamified e-quizzes and conventional online quizzes for their class engagement. The participants were 130 female university students in Seoul with various majors. As a quasi-experimental study, this study compared the attitudes of a gamified e-quiz group ( $n=92)$ and a conventional online quiz group $(n=38)$ after experiencing their respective quiz intervention of either nine gamified e-quizzes or nine online quizzes over a 15 -week semester. Each group responded to a survey at the end of the semester. The quantitative analyses of the surveys indicated that the perception of the two groups did not display statistically significant differences, each displaying positive views toward their quiz interventions for emotional, behavioral, and cognitive engagement. In addition, the two groups demonstrated neutral to positive attitudes for each quiz intervention for agentic engagement. Among many reported benefits, the students in both groups expressed that the quiz experiences facilitated them to understand the content knowledge and enjoy the assessment activities. These two advantages of the two quiz modes were seen to be related to close student-teacher interaction.
\end{abstract}

Keywords—gamification, gamified e-quiz, engagement, perception study, online assessment

\section{Introduction}

Online courses have been seen as an alternative or support to traditional face-toface classes. As online courses require minimal direct interaction between students and teachers, extra attention has to be paid to student engagement. Although both offline and online courses require student engagement for effective learning, maintaining student engagement in online classes seems more challenging due to the physical distance between students and teachers online [1].

For the last decade, gamification has been evolving in education, as has its influence on student learning [2]. Gamification, which is defined as using "game design elements in non-game contexts" ([3], p. 9), has been studied for its potential to induce student engagement and motivation in learning and teaching [4]. It is also believed to improve learner participation and interaction and to stimulate learners to increase their knowledge $[2,5]$. As one of the innovative online techniques, gamification has been 
utilized for interactive teaching and learning in online courses [6]. Many researchers have studied its relationships with student engagement because the gamification approach makes learning enjoyable through promoting friendly competitions and rewards [7]. Moreover, it allows instructors to monitor and assess students' learning processes [8] and provides feedback based on the assessment. The gamification of quizzes as a formative assessment has emerged as an extensive research area.

Several researchers have examined this research topic for the last few years [2, 9]. Some studies $[10,11]$ have reported positive impacts, whereas others $[12,13]$ have found adverse effects. Given the mixed findings, it is not easy to make any definitive statements regarding the impact of gamified quizzes on students' learning or class engagement.

Therefore, this study investigated the impact of gamified e-quizzes as a formative assessment for students' engagement in an online course. For comparative analyses, the study was designed to compare the attitudes of two groups of students toward their engagement after the intervention of gamified e-quizzes or conventional online quizzes were implemented for each. To that end, this paper has sought to answer the following research questions:

1. How do the students in a gamified e-quiz group (Group A) and a conventional online quiz group (Group B) perceive their interventions for their engagement?

2. Is there a difference in the student attitudes towards students' engagement between the two groups?

3. What are the shared thoughts of the two groups after experiencing each quiz?

\section{$2 \quad$ Literature review}

For the last decade, researchers have sought to merge information communication and technology (ICT) into teaching and meet the educational needs of digital natives who grew up with technology and live and work online in their daily lives $[14,15]$. Meanwhile, gamification has emerged as an effective tool for educators to improve the digital native's learning outcomes [16, 17].

The term gamification refers to using game mechanics and characteristics in nongame contexts to facilitate individuals to reach their goals [3]. Under the fundamental premise that games are enjoyable [18], much research has been implemented to induce the students to engage in the learning process [19] and increase the learning outcomes [20].

Some studies have investigated the impact of gamified quizzes in an educational setting, rendering positive outcomes such as increased class engagement, knowledge retention, and cooperative learning $[10,11]$. A recent study [21] examined if a gamified e-quiz benefited children's reading habits, academic performance, reading competency, and motivation. Using a mixed-method research design, the researchers gathered survey data from thirty-nine students, twenty-three parents, and seven teachers; and interviewed thirty-seven students, twenty parents, and seven teachers after using Reading Battle, a gamified e-quiz bank designed to develop children's reading skills. Through the analyses, the researchers found that the gamified e-quiz experience 
had been perceived to be helpful to students' reading habits, academic performance, reading competency, and reading motivation. Most of the students indicated that the gamified e-quizzes had changed their reading habits, mainly a higher reading frequency and a more comprehensive book choice range. The students also reported that they were both extrinsically (e.g., the leaderboard) and intrinsically (e.g., a sense of achievement) motivated to read more. The findings of the study demonstrated how gamified e-quizzes could encourage children's reading practices. The study also described how the gamified e-quizzes effectively facilitated the students to read books autonomously.

In another study [22] displaying the positive impact of gamified e-quizzes, the researchers aimed to examine the impact of gamified e-quizzes on students' learning motivation. For the study, the researchers provided eighteen students in a class for studying TOEFL at a university in Surakarta with gamified e-quizzes on the Quizizz platform. The researchers gathered data through a questionnaire, observations, and indepth interviews. The analyses indicated that the gamified e-quizzes positively impacted students' learning motivation, illustrating that the students were motivated to learn more on subjects covered on the quiz. The study suggested that the students could have been engaged due to the examinations' gamified elements. These elements included time restriction, meme, test report, and leaderboard.

This study aptly addressed the concept of test impact, which is the washback of the gamified e-quizzes. The researchers discussed how gamification could be applied to facilitate students' learning motivation leading to beneficial washback. The study demonstrated that gamified e-quizzes increased the students' learning motivation through the game elements such as leaderboard, meme, time limit, and test report that the e-quizzes provided, and the students enjoyed the assessment processes.

Unlike the gamification studies, which showed the positive side of the approach, several studies have had less positive or mixed results. When using the gamified element of collecting badges, a study found that the students had mixed views about acquiring badges on their academic motivation [12]. In the study, a new reward system with badges was added to a course managed with an automatic assessment system. To examine the impact of the gamified element on student behaviors, the researchers employed 162 university students out of 306 registered in a computer programing course. The participants responded to a survey after experiencing four rounds of assessments with badges. Specifically, the badges were awarded based on three criteria that included learning achievement (test score), time management (submission date), and carefulness (trial frequency). The badges were awarded in three levels of bronze, silver, and gold, depending on an increase in completion difficulty. The students' badge collections were not reflected in their course grades as in other gamification studies.

The results of the study revealed assorted responses from the students. Although most students enjoyed collecting the badges, some expressed strong negative perceptions about it. The negative responses seemed to be related to adding the badge system to the course's already existing automatic assessment procedures. The preexisting assessment was managed as it used to be, and its scores were reflected on the students' grades independently from the badge system. The course's assessment sys- 
tem even deducted points against the carefulness criterion if the students took the quizzes multiple times, which could have influenced the students' affections about the activities. Thus, this study seems to be an example displaying that grafting a gamified element on the pre-existing quiz system may not work as the gamification of the assessment. As the essence of a gamified e-quiz is in inducing participants' engagement through enjoyable activities, a gamification study is expected to be carried out in a less stressful environment. Probably the assessment procedure of the study might not have been an enjoyable and less anxious process which might have influenced the result of the study.

The results of another study reported that gamification could decrease students' learning pleasure and motivation [13]. The researchers examined two groups-one gamified instruction group and one comparison group without the gamified instruction-measuring students' motivation, social comparison, effort, satisfaction, learner empowerment, and academic performance during a 16-week duration. According to the study, the gamified group displayed less motivation, satisfaction, and empowerment than those in the comparison group. Students in the gamified group earned lower final test scores than the comparison group. The researchers concluded that their study is a case where giving rewards such as badges and coins and encouraging competition through leaderboards could negatively influence students' motivation.

Both studies have shown that the gamified approach could negatively impact students' motivation [12, 13], class engagement, and learning performance [13]. The common aspect of the two studies was using external factors such as reward systems to induce students' learning motivation and academic performances. This reliance on an external reward system might have excluded the students from the autonomous role in the learning process. Moreover, using only one gamified element might not be sufficient to engage students in the learning process.

A more sophisticated gamified quiz was implemented in the following study [23]. This quasi-experimental study with an archival data set investigated the impact of gamified quizzes on student learning comparing two groups $(\mathrm{N}=473)$--a gamified equiz group $(n=316)$ and a traditional quiz group $(n=157)$ [23]. The researchers hypothesized that students in the gamified intervention would complete more quizzes and, through the testing effect, would lead to better learning. During a 16-week semester, the two groups were compared through three consecutive tests, each covering multiple chapters of class material. Test A in week 5, Test B in week 8 , and Test $\mathrm{C}$ in week 13 were administered, each with 55 multiple-choice questions. The test scores and quiz scores were gathered, and student information and final grades were also collected for analysis. The students in each group were provided with 34 online quizzes made of five multiple-choice tasks in either traditional or gamified form. The two online quizzes differed only in their format. The traditional quiz was designed in a conventional online test format, including questions, answer choices, and a next button. The gamified quiz was made with three elements: progress bar, wager option (deleting two distractors for a hint), and encouraging message.

Through the analyses, the researchers found their data confirmed the previous test impact studies. In the study, the more quizzes the students took, the better they did on the three tests, clearly illustrating the testing effect of the examinations. However, 
unlike their theoretical assumptions about gamification, the testing effect was observed regardless of the quiz mode, showing that the gamified group did not perform better than the traditional group. The positive impact of gamification was not observed in all three assessments but merely demonstrated on the first test. The gamified group gained significantly better scores on Test A exclusively. The researchers explained that the outperformance of the gamified group on the initial test was mainly due to a novelty effect. They suggested that the students' initial interests and usefulness of gamification might have decreased with use.

The study included many participants differentiating itself from most gamification studies, often limited to a small scale by employing the archival data set. Due to the sample size, the researchers performed statistical tests with analyses and aptly used them to answer the research questions. Moreover, unlike some gamification studies comparing gamified quizzes and paper-based quizzes [24], the researchers made their study more reliable by conditioning the two groups with identical online quizzes, treating one group with three gamified elements.

As shown in the literature review, studies on gamification have been growing for the last few years, displaying both positive and negative impacts. However, empirical studies on gamified learning and gamified e-quizzes are still in need, and particularly, more empirical studies are needed investigating the effects of gamification on formative assessment. Thus, the current study compared the students' perceptions of their class engagement after the intervention of gamified e-quizzes or conventional online quizzes.

\section{$3 \quad$ Methodology}

\subsection{Participants}

The participants were selected from one of the researcher's online courses, an elective general English course targeted for sophomores at a women's university in Seoul, S. Korea. For the gamified e-quiz group (Group A), two classes - one from the 15week Spring 2020 semester and the other from the 15-week Fall 2020 semesterwere chosen; for the conventional online quiz group (Group B), one class from the 15-week Spring 2021 semester was used. All three classes were the same English grammar course designed for non-English major students. For the survey, 92 students from Group A and 38 students from Group B responded. All 130 students were females in their twenties, and their majors were very diverse, including twenty different areas of study across eight colleges.

\subsection{Instrument}

Quizzes and feedback. The two types of quizzes were designed with identical questions and written feedback differed only in format (see Figure 1). For Group A, gamified e-quizzes were constructed using the Quizizz platform (https://quizizz.

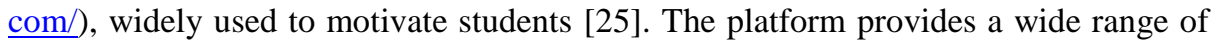


gamified elements, including avatars, leaderboards, memes, music, themes, and time constraints for engaging learning activities. For Group B, conventional online quizzes were provided using the school's LMS platform with the same questions as the gamified e-quiz.

For each 15-week semester, nine quizzes were used covering the textbook, Grammar in Use [26]. Each quiz was designed with nine to twenty items, averaging 15.66 items based on the class contents covered. The examinations were primarily made with true/false tasks and multiple-choice tasks for the students' self-assessment of the class video lessons they had viewed.
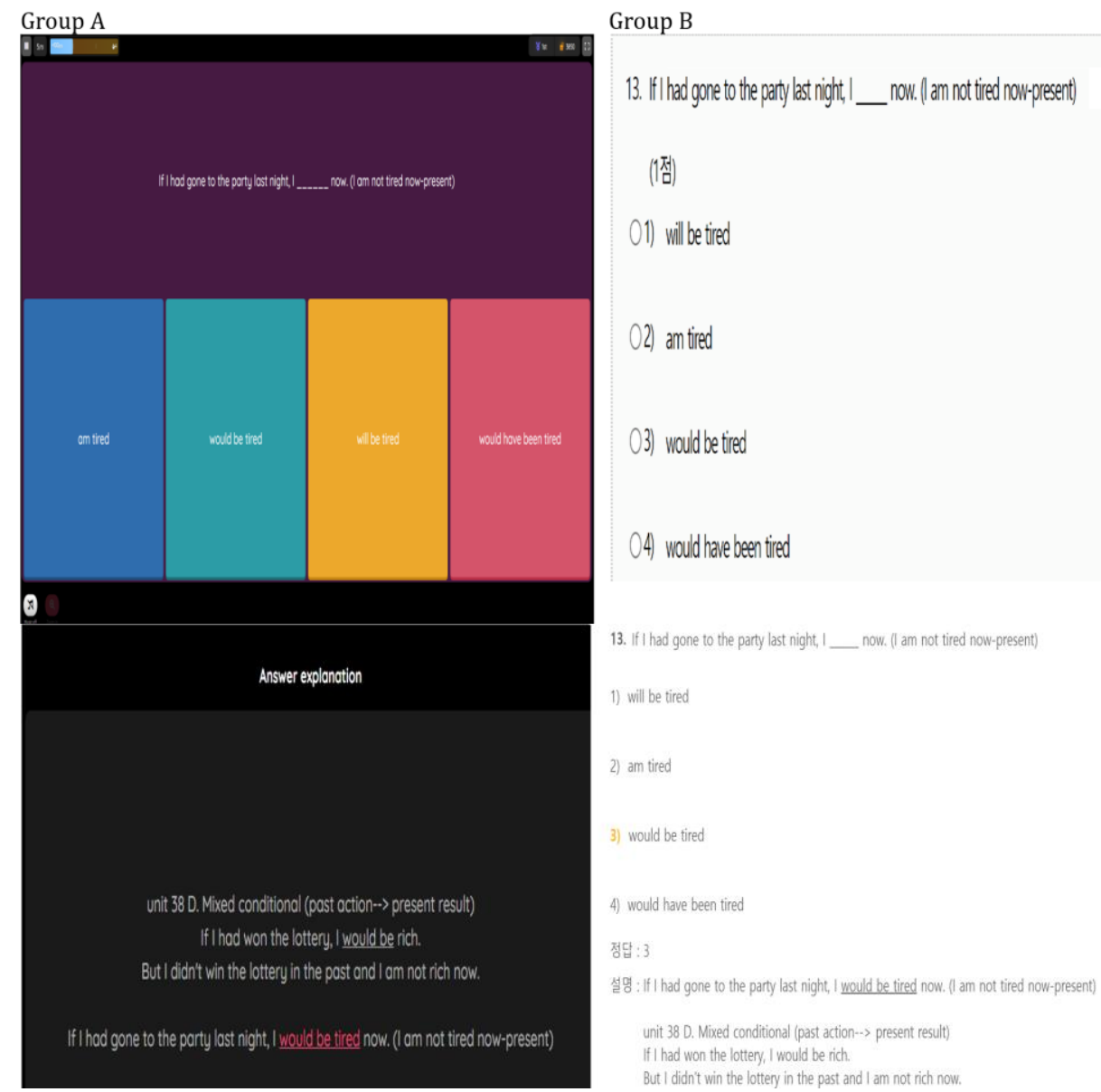

Fig. 1. Quiz and feedback samples for group A and B

In addition to the quizzes and written feedback, the two groups were also provided with feedback videos. The researcher constructed the feedback videos that covered each quiz question and essential points to remember (see Figure 2). 

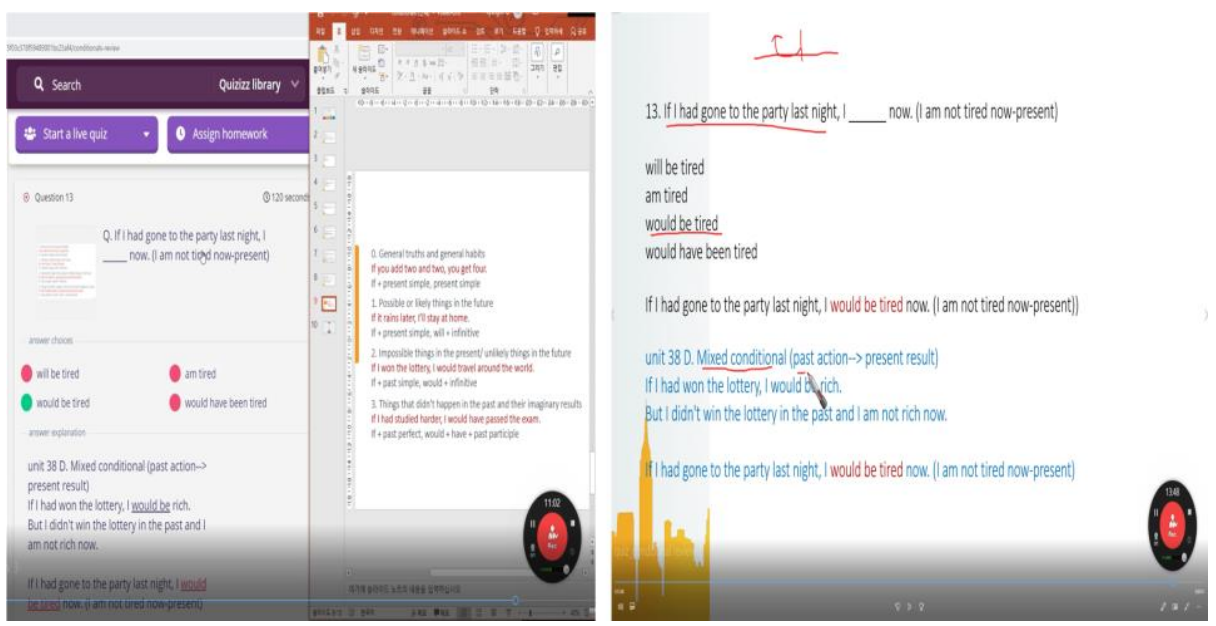

Fig. 2. Feedback video samples for group A and B

Questionnaire. The questionnaire of the study included thirteen Likert scale items and five open-ended questions (See Appendix). The Likert scale was selected from the twenty-four questions on a 5-point Likert scale from [9], which was adopted from [27]. In [27], a scale was developed with twenty-two questions on a 7-point Likert scale to investigate if the agentic domain can be included as part of an engagement construct. Zainuddin et al. [9] modified the scale into twenty-four items for their study, examining the relationship between the gamification approach and students' engagement. In [9], seven interview questions were utilized to validate the Likertscale items. Out of the seven, this study selected five and included them in the survey with minimal revision to collect qualitative data. Since the five open-ended questions were provided in the online poll, it was necessary to avoid survey fatigue by adding too many items. Thus, thirteen Likert scale items were exclusively used with minimal revision from the twenty-four to avoid such an issue by deleting redundant items. The Cronbach alpha value of the Likert scale items was calculated to measure the questionnaire's internal consistency. The estimated value was 0.92 , illustrating that the scale was acceptable to be employed as it is more significant than the minimum internal consistency coefficient of .70 [28].

\subsection{Procedure}

This research project was implemented on an English grammar course during three 15-week semesters from Spring 2020 to Spring 2021. A class with 40 registered students from Spring 2020 and 59 from Fall 2020 were offered gamified e-quizzes. In Spring 2021, a class with 39 registered students was treated with the same quiz items using the educational LMS provided by the university. The former two classes were chosen for Group A, and the latter one was named Group B.

In the first session for each group, the students were introduced to the concept of each intervention and learned how to take gamified e-quizzes/online quizzes. The 
students were also told that the results of the examinations would not be reflected in their grades. After the orientation, the online video lessons for the two groups were carried out asynchronously. The two groups were provided with video lessons with multiple 5 to 20-minute video clips covering the course content on PPT slides. After completing a few sub-units or a unit, a gamified e-quiz or online quiz was provided for students' self-assessment. For successful formative assessment, the students were provided with three types of feedback opportunities.

First, the students were provided with written feedback during or after taking the quizzes. The written feedback was usually a summary of the assessed content. Second, they were also provided with video clips of the researcher's/instructor's explanations of the quiz items. After taking the quizzes, the students were expected to watch video clips of the researcher's/instructor's illustrations of all the quiz items. Lastly, a Q\&A was possible almost whenever the students wanted. Students were allowed to ask any questions through the Naver Café (https://section.cafe.naver.com/ ca-fe/) messaging system that would send out an instant alert to the instructor.

For more interactive feedback, two live sessions for each group were provided. Students in Group A participated in live gamification activities during the sessions, whereas the students in Group B participated in conventional online quiz activities. For communicating with the students, Zoom and Naver Café group messaging were used.

During the 15 weeks, the students in each group solved nine gamified e-quizzes or nine conventional online quizzes to measure their understandings of the course materials. At the end of the semester, an online survey was implemented for each group. Out of Group A, 92.93\% responded to the survey; and out of Group B, 97.44\% participated. In the survey, the students were allowed to respond in any language they wanted to.

\subsection{Data analyses}

To analyze the quantitative data, SPSS version 26 was used. The ordinal variables from the survey data were typically too skewed to meet the assumption of normality of standard statistical tests. In such a case, non-parametric analyses are often used. Although they are less powerful than parametric analyses, the non-parametric alternatives are beneficial since they are free from the normality assumption. Thus, for analyzing the quantitative data, the Mann-Whitney $U$ test was used for the analyses. The test was chosen since its only assumption is that the groups are independent, and the response data are ordinal $[29,30]$.

The qualitative data from the open-ended survey were analyzed using NVivo 12 [31] and Microsoft Excel [32]. Several English responses were directly quoted, and some reactions provided in Korean were translated into English and quoted. 


\section{$4 \quad$ Results}

\subsection{Gamified e-quiz vs. conventional online quiz}

How did the students in Group A and B perceive their quizzes for their class engagement? The descriptive statistics showed both groups of students thought of each intervention positively overall, with minimal differences (see Table 1).

Table 1. Descriptive statistics of the two groups' Likert scale responses

\begin{tabular}{|c|c|c|c|c|}
\hline \multirow[t]{2}{*}{ Engagement } & \multicolumn{2}{|c|}{ Mean (SD) } & \multicolumn{2}{|c|}{ Median } \\
\hline & Group $A(n=92)$ & Group $B(n=38)$ & Group A & Group B \\
\hline \multicolumn{5}{|l|}{ Emotional } \\
\hline 1. Interest & $4.35(.67)$ & $4.32(.70)$ & 4.00 & 4.00 \\
\hline 2. Motivation & $4.17(.85)$ & $4.37(.79)$ & 4.00 & 5.00 \\
\hline 3. Enthusiasm & $4.14(.72)$ & $4.16(.68)$ & 4.00 & 4.00 \\
\hline 4. Enjoyment & $4.35(.64)$ & $4.39(.55)$ & 4.00 & 4.00 \\
\hline \multicolumn{5}{|l|}{ Behavioral } \\
\hline 5. Participation & $4.35(.70)$ & $4.37(.63)$ & 4.00 & 4.00 \\
\hline 6. Hard Work & $4.38(.71)$ & $4.26(.79)$ & 4.50 & 4.00 \\
\hline 7. Independent Learning & $4.42(.65)$ & $4.53(.60)$ & 5.00 & 5.00 \\
\hline 8. Active Responding & $4.24(.75)$ & $4.37(.71)$ & 4.00 & 4.50 \\
\hline \multicolumn{5}{|l|}{ Cognitive } \\
\hline 9. Achievement & $4.28(.60)$ & $4.40(.64)$ & 4.00 & 4.00 \\
\hline 10. Memory Retentions & $4.28(.68)$ & $4.26(.69)$ & 4.00 & 4.00 \\
\hline 11. Critical Thinking & $4.21(.75)$ & $4.48(.65)$ & 4.00 & 5.00 \\
\hline \multicolumn{5}{|l|}{ Agentic } \\
\hline 12. Expressing one's needs & $4.00(.86)$ & $4.11(.80)$ & 4.00 & 4.00 \\
\hline 13. Active Participation & $3.48(.97)$ & $3.66(.94)$ & 3.00 & 4.00 \\
\hline
\end{tabular}

The students in both groups displayed positive $(M d n=4.00)$ or very positive $(M d n$ $=5.00$ ) views to the items asking about the sub-variables, emotional, behavioral, and cognitive engagement. However, the two groups showed a discrepancy in agentic engagement. To the two items, \#12 and \#13, inquiring about agentic engagement, Group A provided neutral and positive answers $(M d n=3.00 \& 4.00)$, whereas Group B provided positive responses $(M d n=4.00)$. Although Group B's reactions to agentic engagement items were positive, the means were relatively lower than those of the other sub-variables. Thus, the student responses to the agentic engagement in both groups seemed somewhat mixed, ranging from neutral to positive.

Specifically, the two groups of students provided similar responses to eight items, $\# 1,3,4,5,7,9,10$, and 12 . To seven out of the eight, most of the respondents provided favorable responses $(M d n=4.00)$, and to one, item $\# 7$, the students in both groups displayed very positive answers.

The group averages were different for the following five items, \#2, 6, 8, 11, 13. To the one out of five, \#6, Group A's answers $(M d n=4.50)$ were more favorable than 
Group B's $(M d n=4.00)$. To the remaining four items, Group B provided more favorable responses than Group A. For instance, to items \#2 and \#11, Group A's dominant responses were positive, whereas Group B's answers were very positive.

Overall, the students in both groups provided positive responses to emotional, behavioral, and cognitive engagement. The two groups seem to show slight differences in agentic engagement, however. Nonetheless, both groups seemed to have less satisfaction with the agentic aspect than the rest three sub-variables. The descriptive statistics show some similarities and differences between the two groups, and the differences were further examined in the next section if these were statistically meaningful.

\subsection{No difference between the two}

The second research question asked if there was a difference in the student attitudes toward using each quiz intervention for their class engagement. The result of the quantitative analyses was negative. The Mann-Whitney $U$ test results rendered no statistically significant difference between the two groups (see Table 2). Both groups of students mostly displayed positive perceptions toward each quiz.

To twelve out of the thirteen Likert scale items, students in both groups answered affirmatively. To only one question, item \#13, the students in both yielded moderate positive responses. According to the Mann-Whitney $U$ test, the two groups' reactions to all thirteen items were not different $(p>.05)$.

Table 2. Mann-Whitney $U$ test result of the Likert scale responses

\begin{tabular}{|c|c|c|c|c|c|c|c|}
\hline \multirow[t]{2}{*}{ Item \# } & \multicolumn{2}{|c|}{ Group A (n=92) } & \multicolumn{2}{|c|}{ Group B $(n=38)$} & \multirow[b]{2}{*}{$\boldsymbol{U}$} & \multirow[b]{2}{*}{$z$} & \multirow[b]{2}{*}{$\begin{array}{c}p- \\
\text { value }\end{array}$} \\
\hline & Mean Rank & $\begin{array}{c}\text { Sum of } \\
\text { Ranks }\end{array}$ & $\begin{array}{l}\text { Mean } \\
\text { Rank }\end{array}$ & $\begin{array}{c}\text { Sum of } \\
\text { Ranks }\end{array}$ & & & \\
\hline \multicolumn{8}{|l|}{ Emotional } \\
\hline 1. Interest & 65.89 & 6062.00 & 64.55 & 2453.00 & 1712.00 & -.203 & .839 \\
\hline 2. Motivation & 63.04 & 5800.00 & 71.45 & 2715.00 & 1522.00 & -1.251 & .211 \\
\hline 3. Enthusiasm & 65.35 & 6012.00 & 65.87 & 2503.00 & 1734.00 & -.078 & .938 \\
\hline 4. Enjoyment & 65.09 & 5988.00 & 66.50 & 2527.00 & 1710.00 & -.218 & .827 \\
\hline \multicolumn{8}{|l|}{ Behavioral } \\
\hline 5. Participation & 65.50 & 6026.00 & 65.50 & 2489.00 & 1748.00 & .000 & 1.000 \\
\hline 6. Hard Work & 66.88 & 6153.00 & 62.16 & 2362.00 & 1621.00 & -.716 & .474 \\
\hline 7. Independent Learning & 64.00 & 5888.00 & 69.13 & 2627.00 & 1610.00 & -.795 & .427 \\
\hline 8. Active Responding & 63.74 & 5864.00 & 69.76 & 2651.00 & 1586.00 & -.906 & .365 \\
\hline \multicolumn{8}{|l|}{ Cognitive } \\
\hline 9. Achievement & 63.52 & 5843.50 & 70.30 & 2671.50 & 1565.50 & -1.051 & .293 \\
\hline 10. Memory Retentions & 65.73 & 6047.00 & 64.95 & 2468.00 & 1727.00 & -.119 & .906 \\
\hline 11. Critical Thinking & 62.27 & 5728.50 & 73.33 & 2786.50 & 1450.50 & -1.660 & .097 \\
\hline \multicolumn{8}{|l|}{ Agentic } \\
\hline 12. Expressing one's needs & 64.27 & 5913.00 & 68.47 & 2602.00 & 1635.00 & -.613 & .540 \\
\hline 13. Active Participation & 63.36 & 5829.50 & 70.67 & 2685.50 & 1551.50 & -1.058 & .290 \\
\hline
\end{tabular}

${ }^{*} p<.05$ 
From this data, students' perceptions of class engagement between the two groups were not statistically significant. Of all the items, the smallest $p$-value was observed in item \#11: $U=1450.50, z=-1.660, p=.097(p>.05)$. As seen in Table 1, although Group B's perception toward the conventional online quizzes $(M d n=5.00)$ was higher than that of Group A for the gamified e-quizzes $(M d n=4.00)$, there was no statistical significance, suggesting that the two groups are homogeneous.

\subsection{The shared thoughts of the two groups after each intervention}

The last research question asked about the shared thoughts of the two groups of students after experiencing each type of quiz. The qualitative data showed the students in each group had favorable perceptions of each quiz experience.

Students in both groups indicated that they favored the quizzes they experienced over paper-based quizzes (See Figure 3). Seventy-five participants (81.52\%) from Group A (n=92) answered they would choose gamified e-quizzes over paper-based examinations, and thirty students $(78.95 \%)$ from Group B $(n=38)$ responded that they would select conventional online quizzes over paper-based ones. Twelve participants (13.04\%) from Group A and six (15.79\%) from Group B indicated they still prefer paper-based examinations to conventional online and gamified e-quizzes. Four individuals $(4.35 \%)$ from Group A and one $(2.63 \%)$ from Group B answered both forms were acceptable. Succinctly, the data analysis suggested that both groups preferred their quizzes over paper-based quizzes.

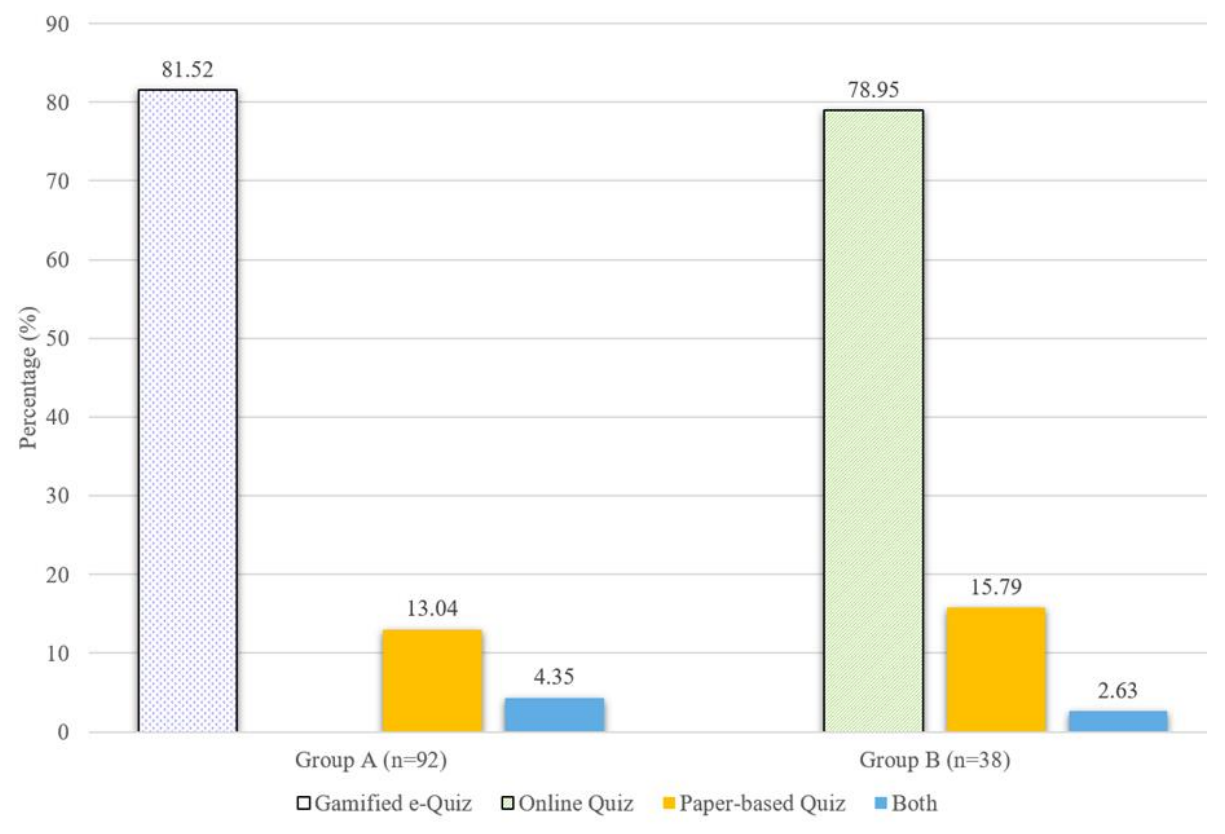

Fig. 3. Preference for each quiz intervention 
To the question asking about the effects of each quiz experience on learning achievement, many students in both Group A and B expressed the positive impact of gamified e-quizzes and conventional online quizzes on their learning achievement (see Table 3).

Table 3. The use of gamified e-quizzes/online quiz on learning achievement

\begin{tabular}{|l|c|c|c|c|}
\hline \multicolumn{1}{|c|}{ Reasons } & \multicolumn{2}{c|}{ \# of Coded Responses } & \multicolumn{2}{c|}{ \% of Coded Responses } \\
\hline & Group A $(\boldsymbol{n}=\mathbf{9 2})$ & Group B $(\boldsymbol{n = 3 8})$ & Group A & Group B \\
\hline Review & 27 & 15 & 29.35 & 39.47 \\
\hline Self-assessment & 19 & 18 & 20.65 & 47.37 \\
\hline Increase Understanding & 17 & 8 & 18.48 & 21.05 \\
\hline Low Anxiety & 6 & 2 & 6.52 & 5.26 \\
\hline Retention & 7 & 1 & 7.61 & 2.63 \\
\hline Test-preparation & 3 & 2 & 3.26 & 5.26 \\
\hline Enjoyable Activity & 28 & 0 & 30.43 & 0.00 \\
\hline Autonomous learning & 3 & 0 & 3.26 & 0.00 \\
\hline Repetition & 3 & 0 & 3.26 & 0.00 \\
\hline Feedback & 3 & 0 & 3.26 & 0.00 \\
\hline Easy Access & 2 & 0 & 2.17 & 0.00 \\
\hline Motivation & 1 & 0 & 1.09 & 0.00 \\
\hline
\end{tabular}

With both groups, the reported beneficial aspects of each assessment were reviewing, self-assessing, and understanding content knowledge, low anxiety, retention, and test preparation. Specifically, the reviewing function was referred by twenty-seven students from Group A (29.35\%) and fifteen students from Group B (39.47\%):

A_ref.\#45: It was beneficial to be able to review what I had learned in class.

Nineteen students from Group A $(20.65 \%)$ and eighteen students from Group B $(47.37 \%)$ also mentioned the self-assessment:

B_ref.\#6: I could see where I was confused and lacking in the content of the class.

In addition, seventeen individuals from Group A (18.48\%) and eight from Group B $(21.05 \%)$ responded that their quizzes helped them increase their understandings of the content knowledge:

B_ref.\#38: By encountering several example sentences, I improved my ability to understand English (grammar use) in different contexts depending on the situation.

To the question about the quiz impact on independent learning skills, students in both groups viewed their quizzes as helpful to their independent learning in terms of autonomous learning, self-assessing, increasing content knowledge understanding, reviewing, etc. (see Table 4). 
Table 4. The use of gamified e-quizzes/online quiz on independent learning skills

\begin{tabular}{|l|c|c|c|c|}
\hline \multicolumn{1}{|c|}{ Reasons } & \multicolumn{2}{c|}{ \# of Coded Responses } & \multicolumn{2}{c|}{ \% of Coded Responses } \\
\hline & Group A $(\boldsymbol{n}=\mathbf{9 2})$ & Group B $(\boldsymbol{n = 3 8 )}$ & Group A & Group B \\
\hline Autonomous learning & 31 & 7 & 33.70 & 18.42 \\
\hline Self-assessment & 19 & 11 & 20.65 & 28.95 \\
\hline Increase Understanding & 17 & 11 & 18.48 & 28.95 \\
\hline Review & 10 & 8 & 10.87 & 21.05 \\
\hline Easy Access & 3 & 2 & 3.26 & 5.26 \\
\hline Low Anxiety & 4 & 1 & 4.35 & 2.63 \\
\hline Motivation & 4 & 1 & 4.35 & 2.63 \\
\hline Retention & 4 & 1 & 4.35 & 2.63 \\
\hline Test-preparation & 2 & 1 & 2.17 & 2.63 \\
\hline Feedback & 1 & 1 & 1.09 & 2.63 \\
\hline Repetition & 14 & 0 & 15.22 & 0 \\
\hline Enjoyable Activity & 7 & 0 & 7.61 & 0 \\
\hline
\end{tabular}

Particularly, thirty-one students from Group A (33.70\%) and seven students from Group B (18.42\%) responded that their quizzes helped them autonomously study the class materials:

A_ref.\#28: It was nice to be able to study alone with the gamified e-quiz.

A_ref.\#40: I started self-study because I solved it over and over again outside of class time.

B_ref.\#18: My willingness for self-study was increased.

In addition, students from each group indicated each quiz experience assisted them in self-assessing (Group A: 20.65\%, Group B: 28.95\%), reviewing (Group A: $10.87 \%$, Group B: $21.05 \%$ ), monitoring their class progresses, and increasing their understanding of the content knowledge (Group A: 18.48\%, Group B: 28.95\%). Students commented on the usefulness of the quizzes for their self-assessment:

A_ref.\#37: It was nice to have objective opportunities to check if I had studied well after studying alone.

B_ref.\#27: It seems like an opportunity to check yourself.

The students' assessments of the quizzes were partly related to the responses to the question about the student-teacher interaction (see Table 5).

Table 5. The use of gamified e-quizzes/online quiz on student-teacher interaction

\begin{tabular}{|l|c|c|c|c|}
\hline \multicolumn{1}{|c|}{ Reasons } & \multicolumn{2}{c|}{ \# of Coded Responses } & \multicolumn{2}{c|}{ \% of Coded Responses } \\
\hline & Group A (n=92) & Group B $(\boldsymbol{n}=\mathbf{3 8 )}$ & Group A & Group B \\
\hline Communication & 28 & 11 & 30.43 & 28.95 \\
\hline Self-assessment & 8 & 9 & 8.70 & 23.68 \\
\hline Teacher's Evaluation & 12 & 7 & 13.04 & 18.42 \\
\hline Feedback & 11 & 5 & 11.96 & 13.16 \\
\hline Teacher's Intension & 13 & 1 & 14.13 & 2.63 \\
\hline Review & 6 & 1 & 6.52 & 2.63 \\
\hline
\end{tabular}


Paper-A Comparative Study of Gamified and Conventional Online Quizzes

\begin{tabular}{|l|l|l|l|l|}
\hline Enjoyable Activity & 6 & 1 & 6.52 & 2.63 \\
\hline Low Anxiety & 4 & 1 & 4.35 & 2.63 \\
\hline Motivation & 4 & 1 & 4.35 & 2.63 \\
\hline Easy Access & 2 & 2 & 2.17 & 5.26 \\
\hline Autonomous Learning & 1 & 2 & 1.09 & 5.26 \\
\hline Increase in understanding & 2 & 1 & 2.17 & 2.63 \\
\hline Test Preparation & 2 & 0 & 2.17 & 0 \\
\hline Repetition & 2 & 0 & 2.17 & 0 \\
\hline
\end{tabular}

Students in both groups (Group A: 30.43\%, Group B: 28.95\%) expressed that their assessment experiences were related to their communication with the instructor:

A_ref.\#30: Communication was possible immediately when there was a need during my completion of the items on the gamified e-quizzes.

A_ref.\#40: It was good because it (live gamification) seemed like a time to communicate with other classmates. During the live activity, the professor encouraged my classmates who did not get high scores.

B_ref.\#30: (Solving the online quizzes) was beneficial in that it allowed me to ask the professor about things I had misunderstood, was confused about, or had questions about.

Other themes in Table 5, including self-assessment, teacher's evaluation, teacher's intention, and feedback, were closely related to student and instructor communication. About the themes of self-assessment and teacher's evaluation, a student from Group A commented:

A_ref.\#61: (Solving the quizzes) was an opportunity for students to understand and review what we had learned and how much we could apply. The teacher was able to check which parts the students were having difficulties with, so it must have been a good resource for determining the direction of a future class.

About the themes of communication and feedback, a student from Group A wrote:

A_ref.\#79: (Solving the quizzes) was good because it seemed like the right time to communicate with the professor. And the professor encouraged the students who did not get high scores during the live gamification online.

With regards to the themes of teacher's evaluation and intention, a student from Group B responded:

B_ref.\#37: (Solving the quizzes) was good for the professor to see what the students lacked. The students could understand what the professor wanted us to understand.

The students' comments demonstrated that both quiz interventions were well suited for the course's formative assessment. Using the messaging app as a supplementary tool for both groups seems to have helped the students connect with the instructor during the online course.

To the question asking if they would like to take another course with their respective quiz experience, fifty-eight students in Group A (63.04\%) and thirty-one students in Group B (81.58\%) responded affirmatively. The percentage of Group A was lower than that of Group B partly because twenty-seven students skipped answering the item $(29.35 \%)$. The reasons for their choices were summed up in Figure 4. 


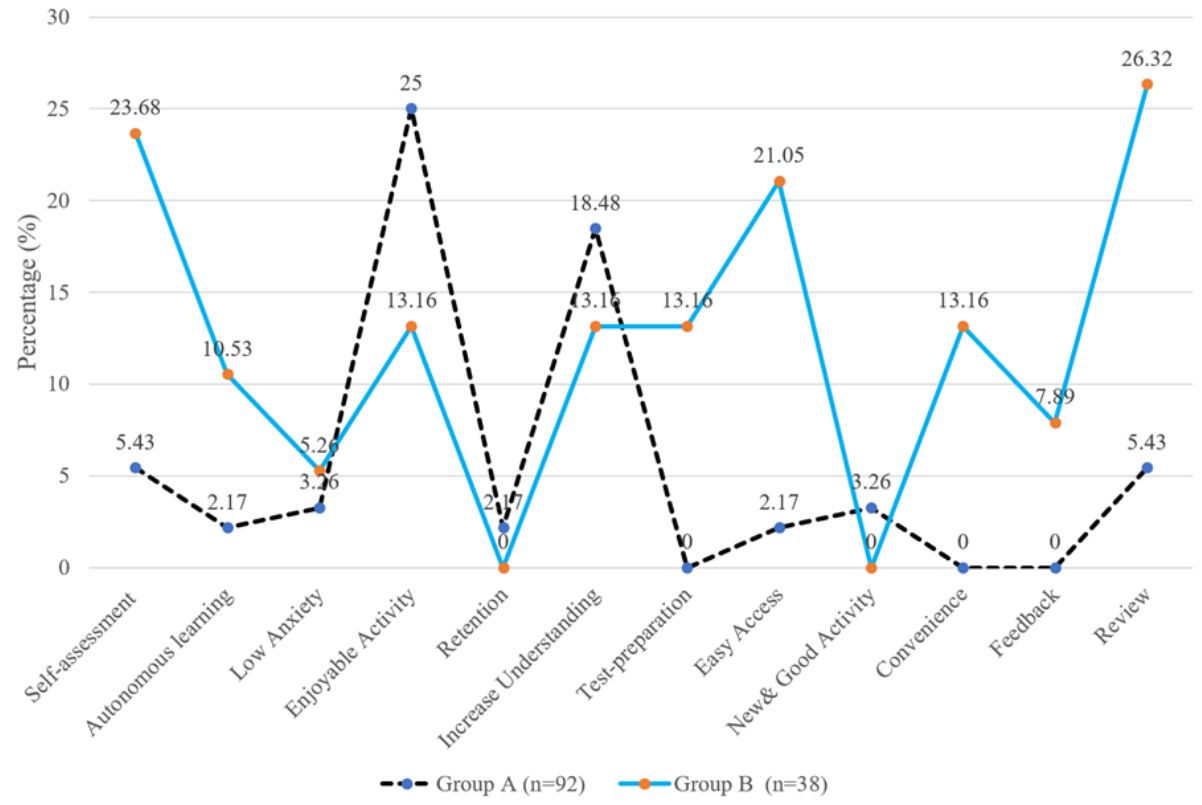

Fig. 4. Reasons for taking another course with the quizzes

The two groups commonly addressed the following seven aspects for explaining their responses for taking another course with each quiz activity: self-assessment, autonomous learning, low anxiety, enjoyable activity, increase understanding, easy access, and review. Among the seven, the two groups' "increase understanding" of the content knowledge and "enjoyable activity" were dominantly shared reasons. Seventeen students (18.48\%) from Group A and five students (13.16\%) from Group B responded that they would take another course with their own quiz experiences because the experiences helped increase their understanding of the class contents:

A_ref.\#53: Because it was possible to easily make up for the missing parts and increase content knowledge.

B_ref.\#5: To increase my content knowledge.

B_ref.\#29: Because I could study more thoroughly.

The student comments illustrated that both types of quizzes were seen to help increase their content knowledge. In addition, twenty-three individuals (25.00\%) from Group A and five (13.16\%) from Group B referred to enjoyable learning experience for describing their choices:

A_ref.\#32: I like the gamification. I felt I was playing games during the study time. It was more enjoyable! It was beneficial, so I would like to take another course using gamified e-quizzes.

A_ref.\#87: I think gamification activity would be good because you can realize that studying can be exciting and enjoyable.

B_ref.\#23: I felt the processes of solving the online quizzes and feedback sessions were enjoyable. 
B_ref.\#25: Because I could enjoy solving the online quiz problems without worrying about grades.

These results display that the students in both classes enjoyed each quiz experience. The comments from the two groups seemed slightly different, however. Many students in Group A expressed that the assessment procedure had been as exciting and enjoyable as playing games. The answers from the five students in Group B seem somewhat different from those of Group A, suggesting the students might have enjoyed the assessment processes. This aspect needs further investigation. Despite the slight difference, many students in Group A and B had positive views of their quiz experiences and believed in the beneficial aspects of the assessments. Therefore, the overall data analyses can be interpreted that the students in each group perceived that the quiz experiences were helpful to their behavioral, cognitive, and emotional engagement in the online courses.

\section{$5 \quad$ Discussion and conclusion}

The purpose of this paper was to examine students' perceptions of using gamified e-quizzes for their class engagement compared to conventional online quizzes. For the study, this paper attempted to answer three research questions. To the first question inquiring how the two groups perceive their experiences for their class engagement, the descriptive data analyses indicated that the students in both groups overall had favorable views toward the intervention for their class engagement. Even though mixed results were observed to an agentic engagement item, most students in both groups had positive perspectives of their quiz interventions.

The second question asked if there was a difference in the student attitudes of the two groups in using each quiz intervention for their class engagement. The statistical analysis suggested that there was no statistically significant difference between them. The students in the gamified e-quiz group and the conventional online quiz group perceived their quiz interventions as beneficial for their class engagement.

To the last question for examining the shared thoughts of the two groups after the intervention, the thematic analyses of the data displayed that the students in both groups thought their quiz experiences were valuable for many reasons. Among the multiple benefits, many students from both groups reported their quiz activities helped them increase their content knowledge and enjoyment of the assessment procedures. These reasons are in part related to the frequent interactions available between the student and the instructor. By comparing the two groups, this study displayed that the students in both groups of gamified e-quizzes and conventional online quizzes perceived their quiz experiences as helpful for their class engagement.

The data from the gamified quiz group confirm several gamification studies $[9,33$, $34,35]$, reporting students' preference for gamified e-quizzes to conventional paperbased quizzes as a formative assessment reflecting the gamified e-quizzes as enjoyable, motivating, and engaging experiences. The conventional online quiz group data support one of the commonly cited benefits of online formative assessments, allowing learners to engage with formative and immediate feedback. Because the students 
could be informed of their learning from the online quizzes and feedback, as suggested in [36], the assessment might have helped them become self-regulating and reflective learners. The benefits of online quizzes were detected from the gamified equizzes as well. Since identical conditions were provided for both groups, the study's communal positive impacts displaying no statistical difference between the two seemed reasonable.

Despite the favorable responses from the participants, this research is limited in a few aspects. As the study used convenience sampling using one of the researcher's courses, the result of the study should not be generalized to other populations. Moreover, this study solely used a survey for data collection, making it impossible to explore student responses further. Specifically, the study could not further investigate the different nature of students' enjoyment between the two groups. If a follow-up interview had been possible, the two groups' responses expressing enjoyable experiences from each intervention might have been further explored. Thus, a more rigorous research design, including random sampling and multiple data collection methods, is needed in future research.

Nevertheless, this study adds empirical research to the gap in gamification research comparing the two online quizzes for class engagement. The paper illustrated that most students in both groups positively perceived their own quiz experiences by conducting quantitative and thematic analyses. This study supports [23], suggesting that it may not be the gamification but the testing impact, which is closely related to the positive testing impact. As Sanchez et al. [23] claimed in their study, frequent quiz administration might be more connected to students' positive perceptions rather than the assessment format itself. In addition, the students' attitudes were also seen to be linked to the detailed feedback and close student-teacher interactions. As emphasized in $[37,38]$, the positive impact of formative assessment lies in a communication process between teachers and students. Using the messaging app for student-teacher interaction and feedback for both groups seems to have made the two quizzes work for students' engagement. The finding is in the same vein as [36], highlighting the benefit of collaborative learning through messaging platforms or team platforms that can offer the opportunity for educator feedback and interaction. Thus, this study reminds the researchers of the importance of fundamental principles of formative assessment, illustrating that a formative assessment designed carefully within a course can help students to be engaged in an interactive learning process.

\section{$6 \quad$ References}

[1] D. Barth, "Seven ways to engaging the online learner to develop self-regulated learning skills," Journal of Teaching and Learning with Technology, vol. 9, no. 1, pp. 19-29, 2020. https://doi.org/10.14434/jotlt.v9i1.29165

[2] D. O. Göksün, and G. Gürsoy, "Comparing success and engagement in gamified learning experiences via Kahoot and Quizizz,” Computers \& Education, vol. 135, pp. 15-29, 2019. http://dx.doi.org/10.1016/j.compedu.2019.02.015

[3] S. Deterding, D. Dixon, R. Khaled, and L. Nacke, "From game design elements to gamefulness: Defining gamification," in Proceedings of the 15th International Academic Mind- 
Trek Conference: Envisioning Future Media Environments, Tampere, Finland, 2011, pp. 9-15. http://dx.doi.org/10.1145/2181037.2181040

[4] M. Khalil, M. Ebner, and W. Admiraal, "How can Gamification Improve MOOC Student Engagement?" in 11th European Conference on Game-Based Learning (ECGBL 2017), Graz, Austria, 2017, pp. 819-828. Available: https://www.researchgate.net/publication/ 320188430_How_can_Gamification_Improve_MOOC_Student_Engagement [Accessed August 18, 2021].

[5] C. E. Lopez and C. S. Tucker, "The effects of player type on performance: A gamification case study," Computers in Human Behavior, vol. 91, pp. 333-345, 2019. https://doi.org/ $\underline{10.1016 / j . c h b .2018 \cdot 10.005}$

[6] N. M. Almusharraf and S. H. Khahro, "Students' satisfaction with online learning experiences during the COVID-19 pandemic," International Journal of Emerging Technologies in Learning (iJET), vol. 15, no. 21, pp. 246-267, 2020. http://dx.doi.org/10.3991/ijet.v15 $\underline{\mathrm{i} 21.15647}$

[7] J. Hamari, D. J. Shernoff, E. Rowe, B. Coller, J. Asbell-Clarke, and T. Edwards, "Challenging games help students learn: An empirical study on engagement, flow, and immersion in game-based learning," Computers in Human Behavior, vol. 54, pp. 170-179, 2016. https://doi.org/10.1016/j.chb.2015.07.045

[8] M. A. Hassan, U. Habiba, F. Majeed, and M. Shoaib, "Adaptive gamification in e-learning based on students' learning styles," Interactive Learning Environments, vol. 29, no. 4, pp. 545-565, 2019. https://doi.org/10.1080/10494820.2019.1588745

[9] Z. Zainuddin, M. Shujahat, H. Haruna, and S. Chu, "The role of gamified e-quizzes on student learning and engagement: An interactive gamification solution for a formative assessment system," Computers \& Education, vol. 145, pp. 1-15, 2020. https://doi.org/10.10 16/j.compedu.2019.103729

[10] L. Hakulinen and T. Auvinen, "The effect of gamification on students with different achievement goal orientations," in 2014 International Conference on Teaching and Learning in Computing and Engineering, 2014, pp. 9-16. http://dx.doi.org/10.1109/LaTiCE.2014 .10

[11] J. Tvarozek and T. Brza, "Engaging students in online courses through interactive badges," In 2014 International Conference on e-Learning, September 2014, pp. 89-95. Available: https://www.semanticscholar.org/paper/Engaging-Students-in-Online-Courses-throughBadges-Tvarozek-Brza/fe685176c8d4bf7f6507f3870815f56a65097c89 [Accessed August 14, 2021].

[12] L. Haaranen, P. Ihantola, L. Hakulinen, and A. Korhonen, "How (not) to introduce badges in online exercises," SIGCSE '14 Proceedings of the 45th ACM Technical Symposium on Computer Science Education, 2014, pp. 33-38. https://doi.org/10.1145/2538862.2538921

[13] M. D. Hanus and J. Fox, "Assessing the effects of gamification in the classroom: A longitudinal study on intrinsic motivation, social comparison, satisfaction, effort, and academic performance," Computers \& Education, vol. 80, pp. 152-161, 2015. https://doi.org/10.101 6/j.compedu.2014.08.019

[14] H. G. Bilgiç, D. Doğan, and S. S. Seferoğlu, "Digital natives in online learning environments: New bottle old wine-The design of on line learning environments for today's generation," in Handbook of Research on Engaging Digital Natives in Higher Education Settings, M. Pinheiro and D. Simões, Eds. Hershey, PA: Information Science Reference, 2016, pp. 192-221. http://dx.doi.org/10.4018/978-1-5225-0039-1.ch009

[15] Z. Y. Liu, Z. A. Shaikh, and F. Gazizova, "Using the concept of game-based learning in education," International Journal of Emerging Technologies in Learning (iJET), vol. 15, no. 14, pp. 53-64, 2020. http://dx.doi.org/10.3991/ijet.v15i14.14675 
[16] F. Oprescu, C. Jones, and M. Katsikitis, "I play at work-ten principles for transforming work processes through gamification," Frontiers in Psychology, vol. 5, no. 14, pp. 1-5, 2014. https://doi.org/10.3389/fpsyg.2014.00014

[17] C. A. Rowland, "The effect of testing versus restudy on retention: A meta-analytic review of the testing effect," Psychological Bulletin, vol. 140, no. 6, pp. 1432-1463, 2014. https:// doi.org/10.1037/a0037559

[18] L.V. Ahn and L. Dabbish, "Designing games with a purpose," Communications of the ACM, vol. 51, no. 8, pp. 58-67, 2008. https://doi.org/10.1145/1378704.1378719

[19] J. Delcker and D. Ifenthaler, "Mobile gamed-based language assessment," International Journal of Emerging Technologies in Learning (iJET), vol. 15, no. 3, pp. 195-206, 2020. http://dx.doi.org/10.3991/ijet.v15i03.11672

[20] N. P. H. Arce and A. M. C. Valdivia, "Adapting competitiveness and gamification to a digital platform for foreign language learning," International Journal of Emerging Technologies in Learning (iJET), vol. 15, no. 20, pp. 194-209, 2020. http://dx.doi.org/10.3991/ ijet.v15i20.16135

[21] X. Li, S. W. Mok, Y. Y. J. Cheng, and S. K. W. Chu, "An examination of a gamified Equiz system in fostering students' reading habit, interest and ability," in $81^{\text {st }}$ Annual Meeting of the Association for Information Science and Technology, Vancouver, Canada, 2018, pp. 290-299. https://doi.org/10.1002/pra2.2018.14505501032

[22] M.D. Pitoyo, S. Sumardi, and A. Asib, "Gamification-Based Assessment: The Washback Effect of Quizizz on Students' Learning in Higher Education," International Journal of Language Education, vol. 4, no. 1, pp. 1-10, 2020. https://doi.org/10.26858/ijole.v4i2.8188

[23] D. R. Sanchez, M. Langer, and R. Kaur, "Gamification in the classroom: Examining the impact of gamified quizzes on student learning," Computers \& Education, vol. 144, pp. 116, 2020. https://doi.org/10.1016/j.compedu.2019.103666

[24] F. Alzaid, "The effects of gamification based formative assessment on motivation and vocabulary acquisition in ESL classroom," M. A. thesis, McGill University, Montreal, 2018. Available: https://escholarship.mcgill.ca/concern/theses/ff3657518 [Accessed August 14, 2021].

[25] T. M. Lim and M. M. Yunus, "Teachers' perception towards the use of Quizizz in the teaching and learning of English: A systematic review," Sustainability 2021, vol. 13, no. 11, p. 6436, 2021. https://doi.org/10.3390/su13116436

[26] R. Murphy, W. R. Smalzer, and J. Chapple, English Grammar in Use: A Self-study Reference and Practice Book for Intermediate Students with Answers. Cambridge: Cambridge University Press, 2018.

[27] J. Reeve and C. M. Tseng, "Agency as a fourth aspect of students' engagement during learning activities," Contemporary Educational Psychology, vol. 36, no. 4, pp. 257-267, 2011. https://doi.org/10.1016/j.cedpsych.2011.05.002

[28] E. Adadan and F. Savasci, "An analysis of 16-17-year-old students' understanding of solution chemistry concepts using a two-tier diagnostic instrument," International Journal of Science Education, vol. 34, no. 4, pp. 513-544, 2011. https://doi.org/10.1080/09500693.20 11.636084

[29] H. B. Mann and D. R. Whitney, "On a test of whether one of two random variables is stochastically larger than the other," Annals of Mathematical and Statistics, vol. 18, no. 1, 50-60, 1947. https://doi.org/10.1214/aoms/1177730491

[30] J. O. Wobbrock and M. Kay, "Non-parametric statistics in human-computer interaction," in Modern Statistical Methods for HCI. Human-Computer Interaction Series, J. Robertson and M. Kaptein, Eds. Springer: Switzerland, 2016, pp. 135-170. https://doi.org/10.1007/97 $\underline{8-3-319-26633-6 \_7}$ 
[31] QSR International Pty Ltd. (2018) NVivo (Version 12). https://www.qsrinternational.com/ nvivo-qualitative-data-analysis-software/home

[32] Microsoft Corporation. (2019). Microsoft Excel. https://www.microsoft.com/en-us/micro soft-365/get-started-with-office-2019

[33] T. Hasegawa, M. Koshino, and H. Ban, "An English vocabulary learning support system for the learner's sustainable motivation," SpringerPlus, vol. 4, no. 1, p. 99, 2015. https://do i.org/10.1186/s40064-015-0792-2

[34] R. Homer, K. F. Hew, and C. Y. Tan, "Comparing digital badges-and-points with classroom token systems: Effects on elementary school ESL students' classroom behavior and English learning," Journal of Educational Technology \& Society, vol. 21, no. 1, pp. 137151, 2018. Available: http://hub.hku.hk/bitstream/10722/243984/1/content.pdf [Accessed August 14, 2021].

[35] E. G. L. Medina and C. P. R. Hurtado, "Kahoot! A digital tool for learning vocabulary in a language classroom," Revista Publicando, vol. 4, no. 12(1), pp. 441-449, 2017. Available: https://revistapublicando.org/revista/index.php/crv/article/view/673 [Accessed August 13, 2021].

[36] T. L. Marquis, "Formative assessment and scaffolding online learning," Special Issue: Evidence-Based Strategies for Facilitating Online Learning, Vol. 2021, no. 169, pp. 51-60, 2021. https://doi.org/10.1002/ace.20413

[37] B. Bahati, U. Fors, P. Hansen, J. Nouri, and E. Mukama, "Measuring learner satisfaction with formative e-assessment strategies," International Journal of Emerging Technologies in Learning (iJET), vol. 14, no. 7, pp. 61-79, 2019. https://doi.org/10.3991/ijet.v14i07.912 $\underline{0}$

[38] G. K. Chung, T. Shel, and W. J. Kaiser, "An exploratory study of a novel online formative assessment and instructional tool to promote students circuit problem solving," The Journal of Technology, Learning and Assessment, vol. 5, no. 6, pp. 1-26, 2006. Available: https://goo.gl/7Md8QT [Accessed: August 14, 2021].

\section{$7 \quad$ Author}

Kyung-Mi O is a Professor in the Department of English at Dongduk Women's University, Seoul, Korea. She received a doctoral degree in language, literacy, and technology specializing in language testing from Teachers College, Columbia University. Her major research interests have been language testing, second language acquisition, and language assessment and technology. Her current research project focuses on technology-enhanced formative assessment.

Article submitted 2021-08-18. Resubmitted 2021-10-27. Final acceptance 2021-10-27. Final version published as submitted by the author.

\section{$8 \quad$ Appendix \& Questionnaire}

The following questions ask you about your current experience of gamified $e$ quizzes/online quizzes. Choose the appropriate number for each statement ( $1=$ strongly disagree, $2=$ disagree, $3=$ neutral, 4=agree, \& 5=strongly agree).

1. When I worked on gamified e-quizzes/online quizzes, I felt interested. 
2. When I answered questions on gamified e-quizzes/online quizzes, I felt curious about the correct answers and my progress scores.

3. I felt enthusiastic about participating in the gamified e-quizzes/online quizzes.

4. I enjoyed learning new things in this class.

5. I actively participated in the gamified/online learning activity.

6. I worked hard to answer quiz questions.

7. I was able to answer quiz questions independently.

8. I tried to be active in answering questions during the gamified/online learning activity.

9. I was able to track my achievement progress after the gamified e-quiz/online quiz activity.

10. I was able to remember the knowledge I gained from the gamified e-quiz/online quiz work.

11. This class helped me to improve my critical thinking skills through various types of quiz questions.

12. I let my teacher know what I needed and wanted.

13. I asked questions to make the class more active and lively.

\section{- Open-Ended Questions}

1. What do you think are the positive effects of gamified e-quizzes/online quizzes on your learning achievement?

2. What do you think are the positive effects of gamified e-quizzes/online quizzes on student-teacher interaction?

3. What do you think are the positive effects of gamified e-quizzes/online quizzes on your independent learning skills?

4. Which form of quizzes do you prefer? Paper-based or gamified e-quizzes/online quizzes?

5. a. Would you like to take another course using gamified e-quizzes/online quizzes?

b. Why? 